\title{
Chemotherapy with Gemcitabine plus Cisplatin in Patients with Advanced Biliary Tract Carcinoma at Chang Gung Memorial Hospital: A Retrospective Analysis
}

\author{
Chiao-En Wu, MD; Hung-Chih Hsu, MD; Wen-Chi Shen, MD; Yang-Chung Lin, MD; \\ Hung-Ming Wang, MD; John Wen-Chen Chang, MD; Jen-Shi Chen, MD
}

Background: A gemcitabine-cisplatin combination is a standard treatment option for patients with advanced biliary tract carcinoma (BTC). We assessed the efficacy and safety of this regimen at Chang Gung Memorial Hospital.

Methods: Between April 2009 and December 2010, 30 chemotherapy-naïve patients (13 men and 17 women; median age: 61.5 years) with advanced BTC were retrospectively analyzed. Treatment consisted of gemcitabine $\left(\mathrm{Gemmis}^{\circledR}\right.$; TTY, Taipei, Taiwan) $1000 \mathrm{mg} / \mathrm{m}^{2}$, followed by cisplatin $30 \mathrm{mg} / \mathrm{m}^{2}$ on days 1 and 8 every 3 weeks. Tumor response was evaluated using the Response Evaluation Criteria in Solid Tumors (RECIST) criteria every 2-3 cycles. The toxicity was assessed by the National Cancer Institute Common Terminology Criteria for Adverse Events, Version 3.

Results: $\quad$ At the end of July, 2011, 27 patients were evaluated using the RECIST criteria. According to the intent to treat analysis of response, 5 patients $(16.7 \%)$ had a partial response, 10 patients $(33.3 \%)$ had stable disease and 12 patients (40.0\%) had progressive disease. The median time to progression (TTP) and median overall survival (OS) of the 30 patients were 4.8 months and 13.4 months, respectively. The patients with biliary obstruction requiring drainage before treatment had a significantly shorter OS than those without biliary obstruction $(p=0.02)$ even though the TTP showed no statistically significant difference $(p=0.69)$ between groups. The major grade III/IV adverse events in the 30 patients included infection $(n=8,26.7 \%)$, anemia $(n=5$, $16.7 \%)$, neutropenia $(\mathrm{n}=4,13.3 \%)$, and elevated alanine aminotransferase $(\mathrm{n}=2,6.7 \%)$. There were no treatment-related deaths.

Conclusions: Gemcitabine plus cisplatin is a feasible chemotherapy regimen with manageable toxicity in patients with advanced BTC. Maintaining good biliary drainage is essential for these patients.

(Chang Gung Med J 2012;35:420-7)

Key words: biliary tract carcinoma, cholangiocarcinoma, chemotherapy, gemcitabine, cisplatin, biliary drainage

\footnotetext{
From the Division of Hematology-Oncology, Department of Internal Medicine, Chang Gung Memorial Hospital at Linkou, Chang Gung University College of Medicine, Taoyuan, Taiwan.

Received: Nov. 30, 2011; Accepted: Apr. 23, 2012

Correspondence to: Dr. Jen-Shi Chen, Division of Hematology-Oncology, Department of Internal Medicine, Chang Gung Memorial Hospital at Linkou. 5, Fusing St., Gueishan Township, Taoyuan County 333, Taiwan (R.O.C.)

Tel: 886-3-3281200 ext. 8825; Fax: 886-3-3278211; E-mail: js1101@adm.cgmh.org.tw
} 
B iliary tract carcinomas (BTC) are heterogeneous malignancies originating from the epithelium of the biliary tract and include cancers of the gallbladder and ampulla of Vater and cholangiocarcinoma (intrahepatic, perihilar and extrahepatic). ${ }^{(1)}$ BTCs are classified into early (resectable), locally advanced (unresectable but not metastatic), and metastatic disease according to the extent of cancer, with the latter two collectively called advanced BTC. Surgical resection is the only curative strategy for patients with early BTC, but more than half of patients are diagnosed with advanced BTC, including those with relapses after curative surgery. ${ }^{(2-4)}$ Advanced BTC has a grave prognosis and the median survival is less than one year in most studies.

Palliative chemotherapy was established by Glimelius et al. in 1996 to improve both survival and quality of life. ${ }^{(5)}$ Subsequently, chemotherapy with fluoropyrimidine (5-fluorouracil (5-FU), capecitabine), and gemcitabine, with or without platinum (cisplatin or oxaliplatin) has been studied, but the optimal chemotherapy regimen has been debated for more than a decade. In Taiwan, the 5-FU-based regimen has been most widely used, with a response rate of around $20 \%$ (Table 1). ${ }^{(6-11)}$

In 2007, Eckel et al. analyzed pooled phase II studies and concluded that gemcitabine combined with platinum compounds represented the provisional standard for chemotherapy. ${ }^{(12)}$ An ABC-02 trial in 2010, the first phase III study for advanced BTC, indicated that the gemcitabine/cisplatin (GEMCDDP) combination should be considered a standard treatment option for these patients. ${ }^{(3)}$ Therefore, we retrospectively assessed the efficacy and safety of this regimen on patients with advanced BTC at Linkou Chang Gung Memorial Hospital (CGMH) in Taiwan.

\section{METHODS}

\section{Patients}

We retrospectively reviewed the medical records of all the patients with BTC consecutively treated between April 2009 and December 2010 at Linkou CGMH. Patients were required to have a histological confirmation of BTC with an inoperable state either because of locally advanced disease or evidence of distant metastasis. All patients had at least one measurable site of disease, an Eastern Cooperative Oncology Group (ECOG) performance status score $\leq$ 2 , an absolute neutrophil count $\geq 1,500 / \mu$ l, a platelet count $\geq 100,000 / \mu 1$, a serum bilirubin level $\leq 2.0$ $\mathrm{mg} / \mathrm{dl}$, and a serum creatinine level $\leq 1.5$ times the upper limit of normal. No prior cytotoxic chemotherapy was allowed. Patients were excluded if they had a history of any other malignancies except for curative treated non-melanoma skin cancer or a cervical intra-epithelium neoplasm within 5 years. Our analysis was approved by the scientific and research ethics committees of CGMH.

\section{Treatment plan}

All chemotherapy-naïve patients with advanced BTC were treated using first-line chemotherapy with a GEM-CDDP regimen. The treatment consisted of gemcitabine (Gemmis $^{\oplus}$; TTY, Taipei, Taiwan) 1000

Table 1. Previous Phase II Studies of Advanced BTC in Taiwan

\begin{tabular}{|c|c|c|c|c|c|}
\hline Authors & Regimen, dose $\left(\mathrm{mg} / \mathrm{m}^{2}\right)$, days & No. of patients & $\mathrm{RR} / \mathrm{SD}(\%)$ & TTP (m) & OS $(\mathrm{m})$ \\
\hline Chen, $1998^{(6)}$ & Weekly 24-h high-dose of F $2600 \mathrm{mg} / \mathrm{m}^{2}$ and LV $150 \mathrm{mg}$ & 19 & $33 / 39$ & 4 & 7 \\
\hline Chen, $2001^{(7)}$ & $\begin{array}{l}\text { MMC } 10 \mathrm{mg} / \mathrm{m}^{2}+\text { weekly } 24-\mathrm{h} \text { F } 2600 \mathrm{mg} / \mathrm{m}^{2} \text { and } \\
\text { LV } 150 \mathrm{mg}\end{array}$ & 25 & $26 / 42$ & 3 & 6 \\
\hline Lin, $2003^{(8)}$ & G $1000 \mathrm{mg} / \mathrm{m}^{2} \mathrm{D} 1,8,15$ every 4 weeks & 24 & $12.5 / 33.3$ & 2.5 & 7.2 \\
\hline Chen, $2003^{(9)}$ & UFT $300 \mathrm{mg} / \mathrm{m}^{2}+$ LV $60 \mathrm{mg}$ D1-28 every 5 weeks & 16 & $0 / 12.5$ & 2.2 & 5.1 \\
\hline Hsu, 2004 & $\begin{array}{l}\text { G } 800 \mathrm{mg} / \mathrm{m}^{2}+\text { weekly } 24-\mathrm{h} \text { F } 2000 \mathrm{mg} / \mathrm{m}^{2} \\
\text { + LV } 300 \mathrm{mg} / \mathrm{m}^{2} \text { on D1, 8, } 15 \text { every } 4 \text { weeks }\end{array}$ & 30 & $21.4 / 46.4$ & 3.7 & 4.7 \\
\hline Chen, $2009^{(11)}$ & $\begin{array}{l}\text { Biweekly 2-day F } 3000 \mathrm{mg} / \mathrm{m}^{2} \text { and } \mathrm{LV} 100 \mathrm{mg} / \mathrm{m}^{2} \\
\text { infusion + Oxa } 85 \mathrm{mg} / \mathrm{m}^{2}\end{array}$ & 32 & $18.8 / 31.3$ & 3.7 & 7 \\
\hline
\end{tabular}

Abbreviations: BTC: Biliary tract carcinoma; RR: response rate; SD: stable disease; TTP: time to progression; OS: overall survival; F: 5-FU; LV: Leucovorin; G: Gemcitabine; MMC: mitomycin C; Oxa: Oxaliplatin; UFT (Tegafur + Uracil); D: Day; h: hour; m: months. 
$\mathrm{mg} / \mathrm{m}^{2}$ followed by cisplatin $30 \mathrm{mg} / \mathrm{m}^{2}$ on days 1 and 8 every 3 weeks. The treatment was continued until disease progression, unacceptable toxicity or patient refusal. Second-line chemotherapy was allowed and the regimen was determined by physician assessment.

\section{Study evaluation}

Tumor response was evaluated by the Response Evaluation Criteria in Solid Tumors (RECIST) guidelines every $2-3$ cycles. Toxicities were assessed based on the National Cancer Institute Common Terminology Criteria for Adverse Events (NCICTCAE, Version 3).

\section{Statistical analysis}

All analyses were performed on an intention to treat basis. The description of the cohort used median and extreme values for categorical variables and percentages with $95 \%$ confidence intervals $(95 \% \mathrm{CI})$ for categorical variables. The overall survival (OS) time was defined as the date from the first treatment to death, last follow-up or data cut-off. Time to progression (TTP) was defined as the date from the first treatment to the earliest date of disease progression, death, last follow-up or data cut-off. Both the OS and TTP were analyzed using Kaplan-Meier curves and the log-rank test.

\section{RESULTS}

\section{Patient characteristics}

There were 32 consecutive patients with advanced BTC screened for this study between April 2009 and December 2010. Two of these patients were excluded because of a history of other primary malignancies, leaving a total of 30 subjects. There were 13 men and 17 women with a median age of 61.5 (range: 38-85). Most $(\mathrm{n}=26,86.7 \%)$ patients had an ECOG performance status of 0-1. The primary site of BTC included intrahepatic $(\mathrm{n}=15,50.0 \%)$, extrahepatic $(\mathrm{n}=3,10.0 \%)$, perihilar $(\mathrm{n}=2,6.7 \%)$ sites, the gallbladder $(\mathrm{n}=4,13.3 \%)$, and the ampulla of Vater $(\mathrm{n}=6,20.0 \%)$. A total of 12 patients $(40.0 \%)$ had obstructive jaundice that required biliary drainage before chemotherapy: 7 had percutaneous transhepatic biliary drainage, 4 had internal biliary stents, and one had both external and internal drainage. The detailed patient characteristics are pro- vided in Table 2.

\section{Efficacy}

By the end of July 2011, 27 patients were evaluated for responses by the RECIST criteria. One patient who refused treatment after the first cycle of chemotherapy and two patients who were lost to follow-up during the first two cycles of chemotherapy were not assessed. According to the intent-to-treat analysis of the responses, none had a complete response (CR), 5 (16.7\%) patients had a partial

Table 2. Patient Characteristics $(n=30)$

\begin{tabular}{|c|c|}
\hline Characteristic & No. of patients (\%) \\
\hline \multicolumn{2}{|l|}{ Gender } \\
\hline Male & $13(43.3)$ \\
\hline Female & $17(56.7)$ \\
\hline \multicolumn{2}{|l|}{ Age, years } \\
\hline Median (range) & $61.5(38-85)$ \\
\hline \multicolumn{2}{|l|}{ ECOG performance status } \\
\hline $0-1$ & $26(86.7)$ \\
\hline 2 & $4(13.3)$ \\
\hline \multicolumn{2}{|l|}{ Number of cycles } \\
\hline Median (range) & $3(0.5-12)$ \\
\hline \multicolumn{2}{|l|}{ Primary site } \\
\hline Intrahepatic & $15(50.0)$ \\
\hline Perihilar & $2(6.7)$ \\
\hline Extrahepatic & $3(10.0)$ \\
\hline Gallbladder & $4(13.3)$ \\
\hline Periampullary & $6(20.0)$ \\
\hline \multicolumn{2}{|l|}{ Extent of disease } \\
\hline Locally advanced & $9(30.0)$ \\
\hline Metastatic & $21(70.0)$ \\
\hline \multicolumn{2}{|l|}{ Previous treatment } \\
\hline Curative surgery & $8(26.7)$ \\
\hline Nil & $22(73.3)$ \\
\hline \multicolumn{2}{|l|}{ Drainage history } \\
\hline No drainage & $18(60.0)$ \\
\hline External drainage & $7(23.4)$ \\
\hline Internal drainage & $4(13.3)$ \\
\hline External and internal drainage & $1(3.3)$ \\
\hline History of biliary tract stones & $6(20.0)$ \\
\hline \multicolumn{2}{|l|}{ Tumor marker } \\
\hline Elevated CA19-9 (>37U/mL) & $23 / 29(79.3)$ \\
\hline Elevated CEA $(>5 \mathrm{ng} / \mathrm{mL})$ & $11 / 27(40.7)$ \\
\hline
\end{tabular}

Abbreviations: ECOG: Eastern Cooperative Oncology Group; CA19-9: carbohydrate antigen 19-9; CEA: carcinoembryonic antigen. 
response (PR), and $10(33.3 \%)$ patients had stable disease $(\mathrm{SD})$, resulting in a response rate ([RR], $\mathrm{CR}+\mathrm{PR}$ ) of $16.7 \%$ and a tumor control rate ([TCR], $\mathrm{CR}+\mathrm{PR}+\mathrm{SD})$ of $50.0 \%$. The other $12(40.0 \%)$ patients showed progressive disease (PD). The median time to progression was 4.8 months $(95 \% \mathrm{CI}$ : 3.9-5.7) and the median overall survival was 13.4 months (95\% CI: 8.9-17.9). The RR, TCR, TTP and OS were, respectively, 22.2\%, 66.7\%, 4.9 months, and 14.5 months in the patients without biliary obstruction and $8.3 \%, 25 \%, 3.2$ months, and 8.9 months in the patients with biliary obstruction requiring drainage. There was no statistically significant difference in the TTP (log-rank, $p=0.69$ ) between groups, but patients requiring biliary drainage had a significantly shorter OS (log-rank, $p$ $=0.02$ ) (Figure). The efficacy evaluation is shown in Table 3.

\section{Toxicity}

The toxicity was assessed in all 30 patients by NCI-CTCAE (Table 4). Hematological side effects were commonly observed, but they were generally mild or moderate. The most common grade 3 or 4 toxicity was infection, which occurred in eight patients $(26.7 \%)$. Among them, 7 patients had biliary tract infections (BTIs) and 6 of them had pre-existing biliary tract obstructions that required biliary drainage before protocol treatment. In addition, 2 patients developed liver abscesses. The other grade 3 or 4 adverse effects included anemia $(\mathrm{n}=5,16.7 \%)$, neutropenia $(\mathrm{n}=4,13.3 \%)$, and elevated alanine aminotransferase $(\mathrm{n}=2,6.7 \%)$.

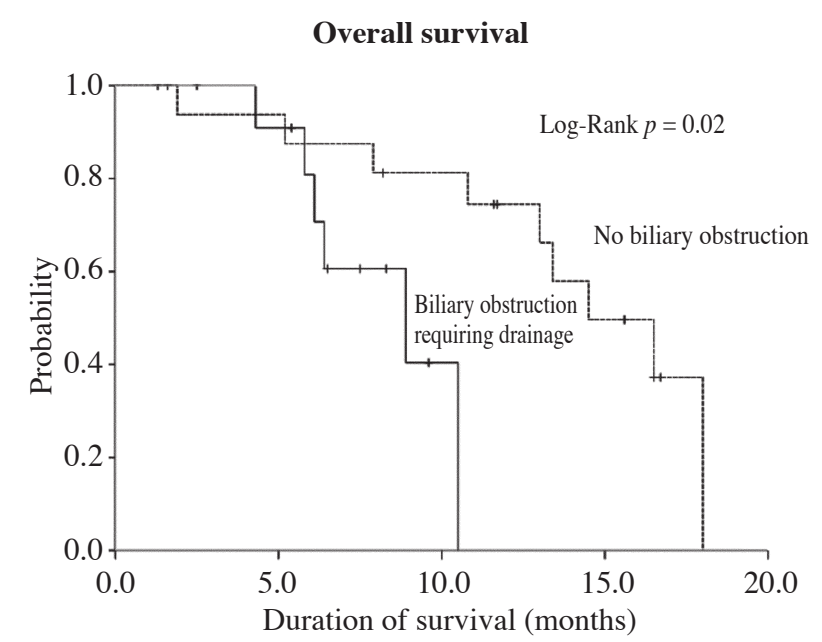

Figure Kaplan-Meier curve of overall survival in patients with biliary obstruction requiring drainage and patients without biliary obstruction.

\section{DISCUSSION}

We retrospectively analyzed the efficacy and safety of chemotherapy with GEM-CDDP, which achieved a TCR of $50.0 \%$, median TTP of 4.9 months, and median OS of 13.4 months. The results on consecutive patients had comparable efficacy with prospective studies of GEM-CDDP including several phase II studies ${ }^{(2,13-23)}$ and one phase III study ${ }^{(3)}$ in selected patients (Table 5). Furthermore, we noted that GEM-CDDP also has a comparable TCR, TTP, longer OS, and less toxicity than has been seen in previous studies involving other regimens for

Table 3. Efficacy Evaluation (intention to treat)

\begin{tabular}{lccc}
\hline & $\begin{array}{c}\text { All patients } \\
(\mathrm{n}=30)\end{array}$ & $\begin{array}{c}\text { No biliary obstruction } \\
(\mathrm{n}=18)\end{array}$ & $\begin{array}{c}\text { Biliary obstruction requiring drainage } \\
(\mathrm{n}=12)\end{array}$ \\
\hline Objective overall response & 0 & 0 & 0 \\
$\quad$ CR & $5(16.7 \%)$ & $4(22.2 \%)$ & $1(8.3 \%)$ \\
PR & $10(33.3 \%)$ & $8(44.4 \%)$ & $2(16.7 \%)$ \\
SD & $12(40.0)$ & $5(27.8 \%)$ & $7(58.3 \%)$ \\
PD & 3 & 1 & 2 \\
No assessment & $50.0 \%$ & $66.7 \%$ & $25 \%$ \\
TCR (CR + PR + SD) & $4.8(3.9-5.7)$ & $4.9(2.1-7.7)$ & $3.2(0.4-6.0)$ \\
Median TTP (months, 95\% CI) & $13.4(8.9-17.9)$ & $14.5(10.4-18.6)$ & $8.9(4.2-13.6)$ \\
Median OS (months, 95\% CI) &
\end{tabular}

Abbreviations: CR: complete response; PR: partial response; SD: stable disease; PD: progressive disease; TCR: tumor control rate; TTP: time to progression; OS: overall survival; CI: confidence interval. 
advanced BTC in Taiwan (Table 1). The longer OS resulted from not only the efficacy of the GEMCDDP treatment, but also advances in providing the best supportive care including carefully managing adverse events from chemotherapy and the complica-

Table 4. Adverse Events in the 30 Patients (NCI CTCAE version 3.0, 2001)

\begin{tabular}{lcc}
\hline & All $(\%)$ & Grade 3 or 4 (\%) \\
\hline Hematologic & & \\
Leukopenia & $7(23.3)$ & 0 \\
Neutropenia & $6(20.0)$ & $4(13.3)$ \\
Anemia & $29(96.7)$ & $5(16.7)$ \\
Thrombocytopenia & $7(23.3)$ & 0 \\
Nonhematologic & & \\
Nausea & $5(16.7)$ & 0 \\
Vomiting & $2(6.7)$ & 0 \\
Diarrhea & $2(6.7)$ & 0 \\
Fatigue & $4(13.3)$ & 0 \\
Infection & $8(26.7)$ & $8(26.7)$ \\
ALT & $13(43.3)$ & $2(6.7)$ \\
\hline
\end{tabular}

Abbreviations: NCI CTCAE: National Cancer Institute Common Terminology Criteria for Adverse Events; ALT: alanine aminotransferase. tions of BTC itself. Therefore, chemotherapy using the GEM-CDDP combination offers a feasible, less toxic regimen in clinical practice.

The most common adverse effect was hematologic toxicity including neutropenia, anemia and thrombocytopenia, but most of these effects were mild and manageable. In addition to myelosuppression, infection, especially in the biliary tract, was a frequent complication, since some of these patients had biliary tract obstructions and required good internal or external biliary drainage. These episodes of infection could delay upcoming anticancer treatment, and make the patient hesitant about chemotherapy, which could then affect the efficacy of chemotherapy.

The risk of BTI is high during chemotherapy even for patients who have adequate biliary drainage for obstructive jaundice before chemotherapy. In one of our previous reports, ${ }^{(7)}$ four patients had treatmentrelated deaths, and 3 of them had percutaneous transhepatic drainage and died of neutropenic sepsis. Hsu et al. evaluated gemcitabine plus a 24-h infusion of high-dose 5-FU /leucovorin and reported 6 of 14 patients with drainage had BTIs. ${ }^{(10)}$ In our present

Table 5. Prospective Studies of Gemcitabine/Cisplatin in Advanced BTC

\begin{tabular}{|c|c|c|c|c|c|}
\hline Authors & $\begin{array}{l}\text { Regimen, dose } \\
\left(\mathrm{mg} / \mathrm{m}^{2}\right) \text {, days }\end{array}$ & $\begin{array}{l}\text { No. of } \\
\text { patients }\end{array}$ & $\begin{array}{c}\mathrm{RR}(\%) / \mathrm{SD} \\
(\%)\end{array}$ & $\begin{array}{l}\text { TTP } \\
(\mathrm{m})\end{array}$ & $\begin{array}{l}\text { OS } \\
(\mathrm{m})\end{array}$ \\
\hline \multicolumn{6}{|c|}{ Phase II studies in advanced BTC } \\
\hline Thongprasert $2005^{(13)}$ & G $1250 \mathrm{D} 1,8+\mathrm{C} 75 \mathrm{D} 1$ & 43 & $27.5 / 32.5$ & 4.7 & 8.3 \\
\hline Lee $2006^{(14)}$ & G 1000 D1, 8 + C 70 D1 & 24 & $20.8 / 50$ & 5.0 & 9.3 \\
\hline Giuliani $2006^{(15)}$ & G $1000 \mathrm{D} 1,8+\mathrm{C} 75-80 \mathrm{D} 1$ & 38 & $32 / 21$ & 4 & $8+$ \\
\hline $\operatorname{Kim} 2006^{(16)}$ & G $1250 \mathrm{D} 1,8+\mathrm{C} 60 \mathrm{D} 1$ & 29 & $34.5 / 13.8$ & 3 & 11 \\
\hline Park $2006^{(17)}$ & G $1000 \mathrm{D} 1,8,15+\mathrm{C} 75 \mathrm{D} 1$ & 27 & $33.3 / 25.9$ & 5.6 & 10 \\
\hline Meyerhardt $2008^{(18)}$ & $\mathrm{G} 1000 \mathrm{D} 1,8+\mathrm{C} 30 \mathrm{D} 1,8$ & 33 & $21 / 36$ & 6.3 & 9.7 \\
\hline Lee $2008^{(19)}$ & G 1250 D1, 8 + C 70 D1 & 35 & $17.1 / 28.6$ & 3.2 & 8.6 \\
\hline \multirow[t]{2}{*}{ Valle $2009^{(2)}$} & G $1000 \mathrm{D} 1,8,15$ & 44 & $22.6 / 35.5$ & 4.0 & NR \\
\hline & G $1000 \mathrm{D} 1,8+\mathrm{C} 25 \mathrm{D} 1,8$ & 42 & $27.8 / 47.1$ & 8.0 & NR \\
\hline \multirow[t]{2}{*}{ Okusaka $2010^{(20)}$} & G 1000 D1, 8, 15 & 42 & $11.9 / 38.1$ & 3.7 & 7.7 \\
\hline & G $1000 \mathrm{D} 1,8+\mathrm{C} 25 \mathrm{D} 1,8$ & 41 & $19.5 / 48.8$ & 5.8 & 11.2 \\
\hline \multicolumn{6}{|c|}{ Phase II studies in advanced gallbladder cancer } \\
\hline Malik $2003^{(21)}$ & G $1000 \mathrm{D} 1,8+\mathrm{C} 70 \mathrm{D} 1$ & 11 & $64 / 18$ & 6.4 & 9.7 \\
\hline Doval $2004^{(22)}$ & G 1000 D1, 8 + C 70 D1 & 30 & $36.6 / 23.3$ & 3.2 & 3.5 \\
\hline Misra $2005^{(23)}$ & G 1000 D1, 8, 15 + C 40 D16, 17 & 40 & $52.5 / 17.5$ & 5.5 & 7.4 \\
\hline \multicolumn{6}{|c|}{ Phase III studies in advanced BTC } \\
\hline \multirow[t]{2}{*}{ Valle $2010^{(3)}$} & G $1000 \mathrm{D} 1,8,15$ & 206 & $14.8 / 56.3$ & 5.0 & 8.1 \\
\hline & $\mathrm{G} 1000 \mathrm{D} 1,8+\mathrm{C} 25 \mathrm{D} 1,8$ & 204 & $25.5 / 55.3$ & 8.0 & 11.7 \\
\hline
\end{tabular}

Abbreviations: BTC: Biliary tract carcinoma; G: Gemcitabine; C: Cisplatin; RR: response rate; SD: stable disease; TTP: time to progression; OS: overall survival; D: Day; m: months; w: weeks; NR: not reported. 
study, half of the 12 patients with biliary drainage had BTIs during treatment. The BTIs occurred more frequently in patients requiring biliary drainage during chemotherapy, so biliary drainage requires additional attention in the treatment plan.

We further analyzed the impact of biliary obstruction in patients with advanced BTC receiving palliative chemotherapy. The patients with biliary obstruction requiring drainage had a significantly shorter OS than those without biliary obstruction $(p$ $=0.02$ ), even though the TTP showed no statistically significant difference between groups. In other words, the patients with biliary obstruction indeed had a poorer prognosis even when drainage was adequate before chemotherapy. Patients with biliary drainage have a high risk of dysfunctional biliary drainage and BTI. To the best of our knowledge, no previous studies have reported that biliary obstruction is a prognostic factor in patients with advanced BTC receiving palliative chemotherapy, so further analysis of prognostic factors in advanced BTC is warranted.

It should be noted that mutation of the epidermal growth factor receptor (EGFR) and overexpression of tyrosine kinase growth factor receptors such as ErbB-2 and EGFR have been identified in a subgroup of patients with BTC. ${ }^{(24-26)}$ Based on these molecular features, targeted monotherapy with erlotinib, cetuximab, lapatinib, and bevacizumab has been studied in BTC. Phase II studies of biochemotherapy combining gemcitabine-oxaliplatin (GEMOX) with cetuximab $^{(27)}$ or bevacizumab ${ }^{(28)}$ showed much higher response rates of $63 \%$ and $40 \%$ which resulted in longer median overall survival times of 15.2 and 14.2 months, respectively. However, the correlation between molecular features and targeted therapy is still unclear and further studies should be conducted to achieve individualized treatment. In fact, a randomized phase II study of GEMOX with or without cetuximab in advanced BTC is ongoing in Taiwan (ClinicalTrials.gov, number NCT01267344), and biomarker prediction will be tested.

This current study has several limitations. First, since this is a retrospective single-institution analysis, we could only evaluate the feasibility of GEMCDDP in our daily practice rather than the efficacy of the GEM-CDDP regimen. Second, treatment with gemcitabine is not reimbursed in patients with advanced BTC by National Health Insurance in
Taiwan. Patients receiving GEM-CDDP as first-line chemotherapy comprised only a small proportion of the entire group, and some of these patients could not maintain chemotherapy until the disease progressed because of economic concerns. Third, we analyzed the impact of biliary obstruction in a single GEMCDDP regimen which cannot represent all palliative chemotherapy. Some confounding factors should have been considered but the number of patients was too small for further univariate and multivariate analysis. Further analysis should be conducted to examine whether biliary obstruction is a prognostic factor in these patients with advanced BTC receiving chemotherapy.

In conclusion, GEM-CDDP is a feasible regimen with manageable toxicity for patients with advanced BTC. With this regimen, patients requiring biliary drainage had a significantly poorer prognosis than those without biliary drainage. Biliary drainage is an important issue in patients whose condition is complicated by biliary obstruction.

\section{REFERENCES}

1. Patel T. Cholangiocarcinoma. Nat Clin Pract Gastroenterol Hepatol 2006;3:33-42.

2. Valle JW, Wasan H, Johnson P, Jones E, Dixon L, Swindell R, Baka S, Maraveyas A, Corrie P, Falk S, Gollins S, Lofts F, Evans L, Meyer T, Anthoney A, Iveson T, Highley M, Osborne R, Bridgewater J. Gemcitabine alone or in combination with cisplatin in patients with advanced or metastatic cholangiocarcinomas or other biliary tract tumors: a multicentre randomised phase II study-The UK ABC-01 Study. Br J Cancer 2009;101: 621-7.

3. Valle J, Wasan H, Palmer DH, Cunningham D, Anthoney A, Maraveyas A, Madhusudan S, Iveson T, Hughes S, Pereira SP, Roughton M, Bridgewater J. Cisplatin plus gemcitabine versus gemcitabine for biliary tract cancer. $\mathrm{N}$ Engl J Med 2010;362:1273-81.

4. Jarnagin WR, Fong Y, DeMatteo RP, Gonen M, Burke EC, Bodniewicz J, Youssef M, Klimstra D, Blumgart LH. Staging, resectability, and outcome in 225 patients with hilar cholangiocarcinoma. Ann Surg 2001;234:507-17.

5. Glimelius B, Hoffman K, Sjoden PO, Jacobsson G, Sellstrom H, Enander LK, Linne T, Svensson C. Chemotherapy improves survival and quality of life in advanced pancreatic and biliary cancer. Ann Oncol 1996; 7:593-600.

6. Chen JS, Jan YY, Lin YC, Wang HM, Chang WC, Liau CT. Weekly $24 \mathrm{~h}$ infusion of high-dose 5-fluorouracil and leucovorin in patients with biliary tract carcinomas. 
Anticancer Drugs 1998;9:393-7.

7. Chen JS, Lin YC, Jan YY, Liau CT. Mitomycin C with weekly 24-h infusion of high-dose 5-fluorouracil and leucovorin in patients with biliary tract and periampullar carcinomas. Anticancer Drugs 2001;12:339-43.

8. Lin MH, Chen JS, Chen HH, Su WC. A phase II trial of gemcitabine in the treatment of advanced bile duct and periampullary carcinomas. Chemotherapy 2003;49:154-8.

9. Chen JS, Yang TS, Lin YC, Jan YY. A phase II trial of tegafur-uracil plus leucovorin $(\mathrm{LV})$ in the treatment of advanced biliary tract carcinomas. Jpn J Clin Oncol 2003;33:353-6.

10. Hsu C, Shen YC, Yang CH, Yeh KH, Lu YS, Hsu CH, Liu HT, Li CC, Chen JS, Wu CY, Cheng AL. Weekly gemcitabine plus 24-h infusion of high-dose 5-fluorouracil/leucovorin for locally advanced or metastatic carcinoma of the biliary tract. Br J Cancer 2004;90:1715-9.

11. Chen JS, Chao Y, Yang TS, Chou WC, Chen LT, Lee KD, Lin YC. A phase II trial of biweekly oxaliplatin with simplified schedule of 48-h infusion of high-dose 5-fluorouracil and leucorvin for advanced biliary tract carcinoma. Cancer Chemother Pharmacol 2009;65:151-7.

12. Eckel F, Schmid RM. Chemotherapy in advanced biliary tract carcinoma: a pooled analysis of clinical trials. Br J Cancer 2007;96:896-902.

13. Thongprasert S, Napapan S, Charoentum C, Moonprakan S. Phase II study of gemcitabine and cisplatin as first-line chemotherapy in inoperable biliary tract carcinoma. Ann Oncol 2005;16:279-81.

14. Lee GW, Kang JH, Kim HG, Lee JS, Jang JS. Combination chemotherapy with gemcitabine and cisplatin as first-line treatment for immunohistochemically proven cholangiocarcinoma. Am J Clin Oncol 2006;29: 127-31.

15. Giuliani F, Gebbia V, Maiello E, Borsellino N, Bajardi E, Colucci G. Gemcitabine and cisplatin for inoperable and/or metastatic biliary tree carcinomas: a multicenter phase II study of the Gruppo Oncologico dell'Italia Meridionale (GOIM). Ann Oncol 2006;17 Suppl 7:vii737.

16. Kim ST, Park JO, Lee J, Lee KT, Lee JK, Choi SH, Heo JS, Park YS, Kang WK, Park K. A Phase II study of gemcitabine and cisplatin in advanced biliary tract cancer. Cancer 2006;106:1339-46.

17. Park BK, Kim YJ, Park JY, Bang S, Park SW, Chung JB, Kim KS, Choi JS, Lee WJ, Song SY. Phase II study of gemcitabine and cisplatin in advanced biliary tract cancer. J Gastroenterol Hepatol 2006;21:999-1003.

18. Meyerhardt JA, Zhu AX, Stuart K, Ryan DP, Blaszkowsky L, Lehman N, Earle CC, Kulke MH, Bhargava P, Fuchs CS. Phase-II study of gemcitabine and cisplatin in patients with metastatic biliary and gallbladder cancer. Dig Dis Sci 2008;53:564-70.
19. Lee J, Kim TY, Lee MA, Ahn MJ, Kim HK, Lim HY, Lee NS, Park BJ, Kim JS. Phase II trial of gemcitabine combined with cisplatin in patients with inoperable biliary tract carcinomas. Cancer Chemother Pharmacol 2008;61: 47-52.

20. Okusaka T, Nakachi K, Fukutomi A, Mizuno N, Ohkawa S, Funakoshi A, Nagino M, Kondo S, Nagaoka S, Funai J, Koshiji M, Nambu Y, Furuse J, Miyazaki M, Nimura Y. Gemcitabine alone or in combination with cisplatin in patients with biliary tract cancer: a comparative multicentre study in Japan. Br J Cancer 2010;103:469-74.

21. Malik IA, Aziz Z, Zaidi SH, Sethuraman G. Gemcitabine and Cisplatin is a highly effective combination chemotherapy in patients with advanced cancer of the gallbladder. Am J Clin Oncol 2003;26:174-7.

22. Doval DC, Sekhon JS, Gupta SK, Fuloria J, Shukla VK, Gupta S, Awasthy BS. A phase II study of gemcitabine and cisplatin in chemotherapy-naive, unresectable gall bladder cancer. Br J Cancer 2004;90:1516-20.

23. Misra S, Chaturvedi A, Misra N. Gemcitabine (G) plus cisplatin $(\mathrm{C})$ in advanced carcinoma gallbladder-A large single center experience. J Clin Oncol 2005;23(16_suppl): 4136.

24. Gwak GY, Yoon JH, Shin CM, Ahn YJ, Chung JK, Kim YA, Kim TY, Lee HS. Detection of response-predicting mutations in the kinase domain of the epidermal growth factor receptor gene in cholangiocarcinomas. J Cancer Res Clin Oncol 2005;131:649-52.

25. Leone F, Cavalloni G, Pignochino Y, Sarotto I, Ferraris R, Piacibello W, Venesio T, Capussotti L, Risio M, Aglietta M. Somatic mutations of epidermal growth factor receptor in bile duct and gallbladder carcinoma. Clin Cancer Res 2006;12:1680-5.

26. Nakazawa K, Dobashi Y, Suzuki S, Fujii H, Takeda Y, Ooi A. Amplification and overexpression of c-erbB-2, epidermal growth factor receptor, and c-met in biliary tract cancers. J Pathol 2005;206:356-65.

27. Gruenberger B, Schueller J, Heubrandtner U, Wrba F, Tamandl D, Kaczirek K, Roka R, Freimann-Pircher S, Gruenberger T. Cetuximab, gemcitabine, and oxaliplatin in patients with unresectable advanced or metastatic biliary tract cancer: a phase 2 study. Lancet Oncol 2010;11: 1142-8.

28. Zhu AX, Meyerhardt JA, Blaszkowsky LS, Kambadakone AR, Muzikansky A, Zheng H, Clark JW, Abrams TA, Chan JA, Enzinger PC, Bhargava P, Kwak EL, Allen JN, Jain SR, Stuart K, Horgan K, Sheehan S, Fuchs CS, Ryan DP, Sahani DV. Efficacy and safety of gemcitabine, oxaliplatin, and bevacizumab in advanced biliary-tract cancers and correlation of changes in 18-fluorodeoxyglucose PET with clinical outcome: a phase 2 study. Lancet Oncol 2010;11:48-54. 


\title{
使用化療吉西他濱 (Gemcitabine) 合併順鉑 (Cisplatin) 在長庚紀念醫院晚期膽道癌患者的經驗：回顧性分析
}

\author{
吳教恩 徐鴻智 沈雯琪 林永昌 王宏銘 張文震 陳仁熙
}

背 景：吉西他濱 (gemcitabine) 合併順鉑 (cisplatin) 在晚期膽道癌是一個標準的化學治療選 擇, 本研究於長庚紀念醫院評估此化學治療處方的療效和安全性

方 法：於 2009 年 4 月至 2010 年 12 月期間, 回顧性分析共 30 例未接受過化學治療的晚期 膽道癌患者 (13 名男性和 17 名女性, 年齡中位數: 61.5 歲)。化學治療處方包括第 1、8 天使用吉西他濱（健任 ${ }^{\circledR}$; 台灣束洋製藥） $1000 \mathrm{mg} / \mathrm{m}^{2}$ 及順鉑 $30 \mathrm{mg} / \mathrm{m}^{2}$, 每 3 週爲一個週期的治療。每 2-3 個週期使用實體腫瘤反應評估標準 (RECIST) 評估腫瘤 反應, 使用美國國家癌症研究院常見毒性標準 (NCI CTCAE) 3.0 版評估毒性。

結 果：至 2011 年 7 月月底, 共 27 例患者使用 RECIST 評估腫瘤反應。根據治療意向分析, 5 例 (16.7\%) 有部分反應, 10 例 (33.3\%) 疾病穞定, 12 例 (40.0\%) 疾病惡化。30 例患 者腫瘤檼化時間及存活時間的中位數分別爲 4.8 個月和 13.4 個月。接受化療前因膽 管阻塞需要引流的患者比沒有膽管阻塞的患者有顯著較短的存活時間 $(p=0.02)$, 即 使兩組在腫瘤惡化時間無統計學顯著性差異 $(p=0.69)$ 。在 30 例患者主要第三、四級 不良事件包括感染 $(26.7 \%)$ ，貧血 $(16.7 \%)$ ，中性顆粒細胞低下 $(13.3 \%)$, 以及丙氨酸 轉氨酶 (ALT) 升高 $(6.7 \%)$, 並沒有治療相關死亡。

結 論：治療晚期膽道癌的患者, 吉西他濱合併順鉑使用是一個合適的化學治療處方, 其毒 性反應是可以處理的。維持良好膽管引流對這些患者是基本必要的。

(長庚醫誌 2012;35:420-7)

關鍵詞：膽道癌, 膽管癌, 化學治療, 吉西他濱, 順鉑, 膽道引流

長庚醫療財團法人林口長庚紀念醫院 血液腫瘤科 ; 長庚大學 醫學院

受文日期：民國100年11月30日；接受刊載：民國101年4月23日

通訊作者: 陳仁熙醫師, 長庚醫療財團法人林口長庚紀念醫院 血液腫瘤科。桃園縣333龜山鄉復興街5號。

Tel: (03)3281200轉8825; Fax: (03)3278211; E-mail: js1101@adm.cgmh.org.tw 